\title{
A Review Essay about Foundations of Neuroeconomic Analysis by Paul Glimcher
}

\author{
Colin F. Camerer*
}

\begin{abstract}
Neuroeconomics aims to discover mechanisms of economic decision, and express them mathematically, to predict observed choice. While the contents of neuroeconomic models and evidence are obviously different than in traditional economics, (some of the) goals are identical: to explain and predict choice, the effects of comparative statics, and perhaps make interesting new welfare judgments that are defensible. To this end, Paul Glimcher's important book carefully describes how economics, psychological, and neural levels of explanation can be linked (a structure which has been successful in visual neuroscience). As Glimcher shows, the neural evidence is quite strong for a process oflearning valuations through prediction error, and a simple model of neural valuation and comparison that corresponds to random utility (though subject to normalization, which produces menu effects). There is also rapidly growing evidence for more complicated constructs in behavioral economics, including prospect theory's account of risky choice, hyperbolic time discounting, level-k models of games, and social preferences corresponding to internal reward based on what happens to other agents. (JEL D01, D03, Y30)
\end{abstract}

\section{Introduction}

$\mathrm{T}$ he splashy attention and criticism of neuroeconomics is a referendum on how curious economists are about how the brain makes economic decisions and whether new insights can tweak old models or inspire new ones.

At one extreme is aggressive disinterest in brain activity. This disinterest is motivated by the methodological history and convention

\footnotetext{
* California Institute of Technology.

$\dagger$ Go to http://dx.doi.org/10.1257/jel.51.4.1155 to visit the article page and view author disclosure statement(s).
}

of economists working extra hard, and ingeniously, to infer unobservables - such as beliefs, utilities, thinking costs, and morefrom observable choices. Other scientific disciplines take an easier route by simply trying to measure the unobservables directly as best they can, as well as inferring unobservables statistically.

At the other extreme is a conviction that progress will certainly be made in understanding the biological basis of economic choice, that such progress will inform "standard" economic concerns (such as predicting choice responses to policy variables), that progress is certainly facilitated by direct 
collaboration and by shared scientific literacy between economists and neuroscientists, and that this is an historically good time to start that collaboration.

The extremely skeptical approach forecasts the time at which neural data is useful as "never." The progressive approach says the time is "someday." Which do you think is likely to prove correct in your lifetime?

This review essay is about the motives, methods, and tentative early findings in neuroeconomics, and where they are between the two extremes. The review part is motivated by the 2011 book Foundations of Neuroeconomic Analysis, by Paul Glimcher. The title is apparently a (perilous?) homage to Paul Samuelson's monumental Foundations of Economic Analysis.

Glimcher's book presents a helpfully clear vision of one part of the progressive approach to neuroeconomics. The titled "foundation" that dominates the book is a simple valueand-compare model in which neural circuits compute random utility for choice objects, then compare them and pick the best one. Glimcher argues that there is actually a natural correspondence between elements of these neural mechanisms and "as if" constructs in standard theory (i.e., utilities and maximization).

The book is not intended to be either an overall, balanced introduction to a rapidlygrowing field, nor a comprehensive textbook. So this essay will first present a broader vision about all the building blocks of neuroeconomics, filling in what readers might want to know about the many other developments in neuroeconomics that are not covered in the book. Then I will comment, as a book critic, on what is both admirable and imperfect about Glimcher's book.

\section{Goals and Methods of Neuroeconomics}

The main goal of neuroeconomics is to supply a mechanistic account of how economic choices are made. As Glimcher and
Rustichini (2004) nicely put it, the goal is a theory that is mechanistic, mathematical, and behavioral. Traditional economic models are both mathematical and behavioral. Typical neuroscience models are mechanistic and behavioral, but rarely mathematical. The shared goal of neuroeconomists, whether from neuroscience or economics, is to have models with all three properties.

Some neuroeconomists are interested in the mechanistic details for their own sake, or for practical purposes, such as associating computational mistakes with mental health disorders (e.g., Kishida, King-Casas, and Montague 2010). Others, like myself, hope that understanding the neural mechanisms will actually improve our ability to understand choice in order to better accomplish traditional goals in economics-predicting choices, predicting responses to changes in prices and other variables, designing institutions that are robust to imperfections in neural implementation, and perhaps in understanding more about welfare.

Please note that all economists who are interested in neuroscience are perfectly aware that the study of brain activity during choice is a radical departure from current standard economic practice. The agnostic disinterest in mechanistic details is very obviously a traditional part of modern revealed preference theory (although not of earlier economic thought). I]

The key step for seeing whether neuroscience can contribute to economics is distinguishing particular methodological approaches in economics from the general

\footnotetext{
${ }^{1}$ It is also noteworthy that many earlier economists including Edgeworth, Fisher, and Ramsey were keenly interested in, and wrote fantastically, about "hedonimeters" and other then-fictional devices for linking biology and choice (Colander 2007). Thus, the modernized reconstruction that "economists were never interested in fleshand-blood human beings" (Gul and Pesendorfer 2008) is wrong (unless Edgeworth et al. are retroactively disbarred from the category "economists" for their speculations).
} 
goal of understanding what causes choice. The proper definition of the scope of economics is a broad one: our goal is to understand the causes of choices and their welfare implications. Aggregation across individuals and institutions such as firms and governments play a special role because those forces produce choice sets, prices, information, and special kinds of constraints (e.g., law).

One way to study the choice process is to assume that unobserved preferences are stable and revealed well by observed past choices. However, there is nothing about the broader desire to understand and predict choices that prohibits other attempts to measure what causes choices by using nonchoice data. That is, inference only from revealed preference is one way to learn about the causes of choices and welfare, but it is not the only way. Other ways are certainly conceivable, and might be better in some respects (e.g., Bernheim 2009).

Importantly, Glimcher correctly notes that linking economics and neuroscience first requires "natural kinds" that are understood in their disciplines. Linking them then requires scientists who understand both natural kinds and agree on some of the ways in which the two kinds are related (though the empirical details of the relation are likely to be under constant debate and revision). Glimcher proposes the term "subjective value" for a neural "kind" and utility_more aptly, decision utility-for the associated economic kind. This view has been implicit in neuroeconomics from the beginning, but Glimcher's persuasive writing creates useful clarity here.

In my view, Glimcher portrays the most traditional economic theorists as more flexible than their writing suggests. He says that Gul and Pesendorfer "argue, [that] economic and neuroscientific analyses are independent and must remain independent as long as the body of economic theory contains no biological concepts of any kind" (Gul and Pesendorfer 2008).

A class of examples that refute the claim of independence of economics and neuroscience is the prediction of actual choices from direct recording of neural activity. This kind of prediction is useful when past choice data are not likely to predict future choices well. Examples include new products, responses to policy changes that are historically unprecedented (e.g., labor markets upon integration of East and West Germany), or when omitted variables in measures of past choices bias estimates. In these cases, a revealed-preference approach based on inference from past data is subject to a variant of the Lucas critique (see Dean 2013).

Some studies have already shown that neural measures during passive viewing of choice objects can predict, to some extent, what choices are later made (see Levy et al. 2010; Smith et al. forthcoming). Neural subjective value reactions to antismoking ads predict whether smokers quit and which televised ads draw the most calls to a help hotline (Falk, Berkman, and Lieberman 2012; Falk et al. 2011). In fact, neural reactions to the ads from a small brain-imaged sample predicted actual hotline calls (by thousands of callers who see the ads on TV) better than subjects' self-reports of ad effectiveness did. What artificial TV-series ideas people choose to forward to others (a measure of "virality") are predicted by activity in mentalizing and reward areas (Falk et al. 2013). These examples suggest the possibility that standard forecasting of future behavior from past choice can be improved if omitted variables (neural measures) are included.

\section{What Neuroeconomics Can Do}

Improved understanding of the link between neural mechanisms and choices is 
likely to lead to three types of support and inspiration for areas of economic theory:

- Neural evidence of utility maximization in simple choice;

- Neural evidence distinguishing different behavioral and rational processes;

- Neural evidence of other psychological influences.

Glimcher's book concentrates on the first kind of evidence. However, the other two types of evidence are likely to grow more rapidly in the years ahead. Therefore, I will describe some of that evidence next.

\subsection{Neural Evidence of Utility Maximization in Simple Choice}

The first general contribution of neuroeconomics will be isolating the neural circuitry of simple choices. In simple cases, this circuitry is likely to produce stable neural measures that correspond to some form of utility maximization. That is, it will not be inaccurate to say that the brain is "computing" utilities (which reliably predict actual choices), much as the visuomotor system of a furniture mover "computes" the likely weight of a chair in order to prepare muscles for lifting.

Glimcher's book is much focused on this first contribution, except for extensive discussion of normalization and relatively brief discussions of challenges to utility maximization.

Note, however, that the decision computations that are likely to fall in this category will be simple: in experiments, they are typically binary choices between two costless rewards that differ on one quality dimension (e.g., amount of juice or taste), which are repeated many times so that the experienced reward value is learned.

Many studies strongly indicate that neural measures of reward value, such as firing rates or blood-oxygen-level dependent (BOLD) blood flow, correspond to values inferred from choice. Human fMRI and other evidence also indicate that this result extends to somewhat more complicated choices (such as food choices and charitable giving). However, nothing is yet known about whether the same types of neural activity compute subjective values for goods or activities that are substantially more complex (health care plans, mates, jobs). And importantly, there is little research on how the neural system accounts for prices or income, time, and attention constraints in the choices made in everyday shopping.

Suppose that the value-and-compare model generates subjective values that match up with inferred utilities in simple cases but not in all cases. What other mechanisms might be at work and how would they fit into economics?

Decades of research with different methods and species suggest there are several neurally distinct sources of subjective valuation or choice. They are sketched in table 1 (see, Rangel, Camerer, and Montague 2008 and references therein for details).

A simple system of some kind exhibits prepared or innate preferences. This system responds to "primary reinforcers," which are goods like food, liquids, warmth, and physical contact that neonate infants "prefer" at birth. A striking example is the preference for looking at faces. Newborns as young as several minutes old prefer to look longer at face caricatures than at visually-comparable scrambled faces, and they stare longer when the faces make eye contact and are lit from above (as if the face is above them) (Valenza et al. 1996; Farroni et al. 2002, 2005). Such innate preferences are likely to be culturally universal, and avoiding choices based on these preferences would be effortful.

The second, "learned" value system is the major topic of Glimcher's book. It is probably the one about which the most is known, partly because it seems to be shared 
TABLE 1

Hypothesized Economic Effects of Different Neural Choice Systems

\begin{tabular}{|c|c|c|}
\hline Neural choice system & Features & Interesting economic effects \\
\hline Prepared (innate) & Primary reinforcers, faces, imitative & "Hard-wired", universal \\
\hline Habit & $\begin{array}{l}\text { Overlearned, low effort, } \\
\text { stimulus } \rightarrow \text { response }\end{array}$ & $\begin{array}{l}\text { Low elasticities in response to outcome } \\
\text { change }\end{array}$ \\
\hline Conditioned learning & $\begin{array}{l}\text { Learning } u \text { (subjective value) over time; } \\
\text { goal-directed }\end{array}$ & Preference changes over time \\
\hline Model-based & $\begin{array}{l}\text { Goal-directed valuation based on } \\
\text { representation; conflicted, "constructed" } \\
\text { preferences }\end{array}$ & Self-control, framing effects \\
\hline
\end{tabular}

anatomically and functionally across species. This system uses reinforcement learning rules (which are well specified mathematically) guided by prediction error to learn subjective values. After sufficient learning takes place, the learned subjective values are likely to be the closest neural computation that we would call, in economic terms, a stable preference for a good.

This learning system is goal-directed: "it depends on a representation of the actionoutcome contingency (that lever pressing produces food: the cognitive map) and on the outcome as a desired goal or incentive (that food is valuable)" (Berridge and O'Doherty 2014, p. 396).

That is, goal-directed valuation attaches value to actions, which are thought (in a sense of mental representation) to achieve goals. Goal-directed valuation is more flexible because it can learn to shift when a valued action is devalued, and will shift to a different action that leads to the valued outcome if the action-outcome contingency is represented.

A special kind of goal-directed valuation is called "model-based." In this case, information about consequences of an action can be computed from a "model" or representation, even if the action has not been chosen and the consequences have not been experienced. This type of valuation is obviously crucial in many complex novel choices humans face. When a new Ph.D. is choosing TIAA-CREF plans on their first job, for example, they have no history of experience making similar choices that has enabled learning of values.

A third system is called "habitual." It associates stimuli to responses (a canonical example is human motor action, as in learning to play a sport). Habits, by definition, do not respond rapidly to changes in the value of outcomes that result from responses. A habit is "outcome-insensitive so that it will persist even after an outcome is no longer valued" (Tricomi, Balleine, and O'Doherty 2009). If one could identify when a human choice response was being implemented by the habit system, one could reliably predict that the short-run elasticity of a habitual response to changes in state variables (outcomes, prices, information) would be low. An everyday example is "outcome-inappropriate cue-driven behavior (e.g., stepping out of an elevator when the doors open, although it has stopped on the wrong floor)" (Tricomi, Balleine, and O'Doherty 2009, p. 2229). A more dramatic canonical example is highly addicted drug users, who overdose when drug purity changes because their dosing 
choice is habitual and does not respond to purity change.

Many of the choices that are considered difficult arise when there is conflict between choices recommended by different value systems. When Bill Clinton was deciding whether to have sexual relations with Monica Lewinsky, a goal-directed system mindful of the chance of being caught and suffering impeachment with highly-evolved prepared (and learned, in Bill's case) valuation of sex. Score: Legacy 0, Sex 1.

\subsubsection{Major Unmet Challenges}

Going beyond the simple settings in which conditioned learning leads to stable preferences presents at least two challenges. First, the basic experiments have no prices or income. Monkeys and people choose among "free" goods or, in some studies, bid for single goods with foregone juice rewards (Platt and Glimcher 1999) or with money. As noted earlier, however, the learning system is ideal for learning valuation but not for trading off different goals (getting the most reward, and spending the least), which is required for responding to changes in prices and income constraint.

It is easy to choose consistently between two juices or foods. Measured efficiency losses from inconsistent (nonmaximizing) choices between two-good bundles are never higher than a few percent, even for people with VMPFC damage (Camille et al. 2011).

However, there are many sources of complexity in naturally-occurring human choices of much interest to economics. Complexity comes from temptation, risk, hidden quality, multiple attributes, future timing, unfamiliarity necessitating goaldirected construction of value, and competition between prepared, learned, and goal-directed systems. Under these conditions, utility maximization is less plausible (especially when the description of goods can affect perceived value).
Furthermore, even going from two to three (or a few) choices complicates the process quite a bit. Working memory could become a constraint on retrieving cached values to compare. The presence of low-quality unchosen objects is also thought to affect values of other objects, in violation of the principle that objects have menu-independent values (Tversky and Simonson 1993). And if the objects have different features that are not integrated into a single object value, then the implicit "agenda" in which one object is compared against the set of two others (Tversky and Sattath 1979) can affect choice, as has been known for decades.

It would be sad if the two-stage back pocket model only works for highly-learned choices among two free goods. As noted earlier, when a habit system makes choices it is unlikely, by definition, that many choices are all separately valued then compared (e.g., the nonhabitual choice will be ignored or underprocessed). And when a goal-directed system selects choices that contribute to different goals—or the basic systems compete in evaluating them, such as sexual temptation competing with avoiding a harassment lawsuit-many models other than the two-stage value-and-compare are likely to operate. Indeed, there is ample evidence that this is so, which is briefly addressed in chapter 15 .

\subsection{Neural Evidence Distinguishing Different Behavioral and Rational Processes}

The second general contribution of neuroeconomics is evidence about whether behavioral economics computations are made by the brain. On this count, the coverage in Glimcher's new book is already well behind the curve, but for a deliberate reason. $\mathrm{He}$ says, "[J]ust as neoclassical theory defined the starting point from which behavioral economics begins its explanation, neoclassically anchored models must serve as the starting point from which neuroeconomics will 
develop as a broadly interdisciplinary field" (p. 389).

I disagree. Neuroclassical models are one starting point for neuroeconomics (a conservative start). However, given rapid progress in behavioral economics, there is no reason to privilege the neoclassical view as a starting point. One could equally well move right away to a search for a general theory of neural choice architecture, expecting to see limiting conditions in which rational choice restrictions hold. Glimcher's rationale for the conservative approach is: "[W]e have just begun to explore the strengths of our neural architecture for choice and valuation. Understanding the weaknesses of that same system will doubtless follow, although that understanding today is in its infancy" (p. 389).

Glimcher may simply not be aware how much we already understand behaviorally about the "weaknesses of that same system"-that is, the limits that psychologists and behavioral economists have been documenting using lab and field choice data since the 1970s. Given this knowledge, accompanying neuroscientific evidence could progress very rapidly, and actually is progressing.

This section will briefly describe progress in just two directions (prospect theory and time preference), then mention findings on other behavioral economics topics.

\subsubsection{Prospect Theory}

The key elements of prospect theory are reference-dependence of outcome evaluation, loss-aversion, and nonlinear weighting of probabilities.

Loss-aversion: Tom et al. (2007) found that across subjects, the difference in brain response to potential loss dollar for dollar, relative to potential gain ("neural loss aversion") was correlated with the degree of loss aversion inferred behaviorally from choices among gambles. (We call this type of correlation "neurometric"). Yacubian et al. (2006), found special gain activity in VStr, and special loss activity in amygdala and temporal lobe regions. De Martino, Camerer, and Adolphs (2010) found that two patients with selective bilateral amygdala lesions exhibited no loss aversion. De Martino et al. (2006) also found that amygdala activity was associated with common choices that reflect framing effects. Sokol-Hessner, Camerer, and Phelps (2013) found that emotionally regulating the reaction to financial loss reduced amygdala activity. All these studies indicate an interesting role for emotion in loss aversion. The fact that monkeys seem to exhibit loss-aversion also indicates that it has a phyologenetically "old" origin that is not unique to humans (Chen, Lakshminarayanan, and Santos 2006; Lakshminarayanan, Chen, and Santos 2008).

Nonlinear weighting of probabilities: Hsu et al. (2009) reported evidence that nonlinearly weighted probabilities of valued outcomes are encoded in the striatum. This finding suggests that such weights reflect genuine preference, rather than, say, a mistake in perceiving probabilities (unless the mistake underlies preference).

\subsubsection{Time Preference}

The neural architecture of expressed time preference is an area in which neuroscience is likely to have a large impact. For example, it is clear that patience in different species, and in the human developmental lifecycle, are associated with brain structure and development (e.g., Rosati et al. 2007). Working memory is also associated with patience, which suggests an important role for "keeping the future in mind" to make patient choices.

The first wave of neuroeconomic studies focused on whether temporal choices depend on two systems, which separately value a present reward (a bird in the hand) and a future imagined reward (two [birds] in the bush). One useful two-system model is the $\beta-\delta$ model of quasi-hyperbolic 
discounting (Laibson 1997). Valuation of a consumption stream at time can be written as, $V(t)=\left(\frac{1}{\beta}-1\right) u\left(c_{t}\right)+\sum_{\tau=0}^{\infty} \delta^{\tau} u\left(c_{t+\tau}\right), \quad \mathrm{a}$ decomposition into a hypervalued initial reward $u\left(c_{t}\right)$ ("inflated" by present bias if $\beta<1$ ) and a conventional exponentially-discounted stream of initial and future utilities. If $\beta=1$ the first term disappears.

McClure et al. $(2004,2007)$ present evidence from choices between money and juice suggesting a $\beta$ "meso-limbic dopaminergic" system (striatum and medial orbitofrontal cortex (MOFC)) and a patient $\delta$ system includes dorsolateral prefrontal cortex (DLPFC) and parietal cortex.

Using a different design with a fixed "present" reward, Kable and Glimcher (2007) fit a unified-value hyperbolic discount function $u\left(c_{t}\right) /(1+k t)$ to brain activity. They conclude that there is only a single system (encoding $u\left(c_{t}\right) /(1+k t)$ ) since regions McClure et al. labeled $\beta$ regions were active when the delayed reward changed.

Kable and Glimcher (2007) vocally argue for the one-system view. However, other kinds of evidence are consistent with some kind of competition between two (or more) types of valuation. For example, Luo et al. (2009) find residual activity in valuation areas for immediate rewards, even controlling for value (as revealed by preference). Sellitto, Ciaramelli, and di Pellegrino (2010) showed that patients with MPFC damage are more impatient than matched neurotypical patients.

A different paradigm investigates selfcontrol during choices that are all immediate. Hare, Camerer, and Rangel (2009) had subjects choose between foods like yogurt and candy bars, which vary in health (longrun benefit) and taste (short-run benefit). DLPFC activity is associated with successful self-control-avoiding tasty unhealthy snacks-by indirectly controlling value encoded in MOFC. A later study disrupting
DLPFC activity—a "temporary lesion"found that such disruption made people more impatient (Figner et al. 2010), as if DLPFC enforces self-control, and disrupting us leads to lapses (and also consistently with McClure et al. 2004, 2007).

These few studies and new ones that are accumulating rapidly, suggest a view in which expressed preference for future rewards is determined by neural activity associated with cognitive control (in DLPFC) and thinking about future (see Peters and Büchel 2010; Carter, Meyer, and Huettel 2010). This hypothesis should not be shocking to economists, since it has often been proposed in the form of multiple-self "planner-doer" models (Thaler and Shefrin 1981; Fudenberg and Levine 2006). However, filling in the neural detail will lead to new comparative static predictions about what mental state variables or exogeneous events change expressed time preference.

For example, Hershfield et al. (2011) found evidence that people were more patient when they interacted with aged versions of their "future selves" using facial-morphing software. It is also well known that prefrontal circuitry, including DLPFC, develops more slowly than reward and affective circuitry in adolescence (Casey, Getz, and Galvan 2008). Given evidence of the role of DLPFC in future valuation and self-control immediately suggests why adolescents are behaviorally impulsive. This is important because many adolescent decisions have long-run consequences (teen pregnancy, schooling choice, smoking, and drug use).

\subsubsection{Other Behavioral Economics Topics}

Social preferences: Behavioral economics has made substantial progress in replacing a simple placeholder of self-interested preference with richer models of social preference for equality, reciprocity, and social image. There is now ample data about how 
hormones, genetics, and brain activity during social choice are associated with social preference (e.g., Fehr and Camerer 2007; Tricomi, Balleine, and O'Doherty 2009; Rilling and Sanfey 2011). The data overwhelmingly support the view that expressed social preferences are based on internal valuations that are traded off with value for one's own payoffs. So far, there is evidence consistent with different types of valuation, including warm glow (Harbaugh, Mayr, and Burghart 2007), inequality aversion (Tricomi, Balleine, and O'Doherty 2009), and social image (Izuma et al. 2011; Izuma, Saito, and Sadato 2010).

Strategic thinking: Mentalizing or "theory of mind" is the capacity, either unique to humans or most reliably developed in us, to imagine what another organism believes, wants, or intends. Obviously such a capacity is presumed by most analyses in game theory.

Studies are beginning to clearly indicate a link between theory of mind regions and game-theoretic computations (see Hampton, Bossaerts, and O'Doherty 2008; Coricelli and Nagel 2009; Camerer and Smith 2012). The data also suggest individual differences that are consistent with a cognitive hierarchy or level-k approach to iterated reasoning (Camerer, Ho, and Chong 2004; Crawford, Costa-Gomes, and Iriberri 2011).

For example, Bhatt et al. (2010, forthcoming) studied a bargaining game with one-sided private information. A buyer observed her hidden value, then stated a (cheaptalk) suggested price to a seller. The seller inferred whatever she could about the hidden value from the suggestion, then stated a take-it-or-leave-it price. Bhatt et al. (2010) found that when buyers were extremely deceptive (level-2), they had more activity in DLPFC and in the temporal-parietal junction (TPJ). Sellers who offered prices that reflected suspicion about whether buyers revealed information about the hidden value had higher activity in amygdala. These findings link computations made in behavioral game theory to brain regions involved in mentalizing "threat" or social fear (amygdala).

Keep in mind that traditional equilibrium analyses say nothing at all about individual differences. Cognitive hierarchy and level-k approaches are one way to do so, and neural activity will help distinguish "good" (highperformance) players from weak players.

Tentative neuroeconomics data are also generally consistent with behavioral economics hypotheses in other domains, including:

- Crowding out of intrinsic incentives (Murayama et al. 2010);

- Negative performance response to very high incentives ("choking") (Chib et al. 2012);

- Overlap in activity during hypothetical and real choice (consistent with overreporting purchase intentions hypothetically), and more activity in real choices in in value-computing areas, for consumer goods (Kang et al. 2011), and in insula and amygdala for "bads" (eating unpleasant foods) (Kang and Camerer 2013);

- Reduced value-related activity when choice sets are larger than ideal due to information processing ("choice overload") (Reutskaja et al. 2011);

- Evidence for computation of "foregone payoffs" or fictive learning in decisions and games, as in EWA learning in games (Camerer and Ho 1999) (see Thevarajah et al., 2009; Zhu, Mathewson, and Hsu 2012);

- Evidence that stock market bubbles are associated with enhanced mentalizing contributes to stock market bubbles (DeMartino et al. 2013) and with heterogeneous trader response to nucleus accumbens signals and to insula "early warning" signals of impending crashes (Smith et al. 2013). 


\subsection{Neural Evidence of Other Psychological Processes}

The most novel contribution of neuroeconomics to economics, per se, may come from supplying evidence about other kinds of complex psychological processes that have been understudied in behavioral economics. In these cases, their complexity makes the axiomatic approach and "as if" testing especially challenging, and possibly inefficient, compared to supplementing theorizing and analysis of field data with information about mechanisms. Here are two loosely sketched examples: addiction and emotion.

Addiction: This is a topic in which both simple extensions of rational choice modeling and biological details have proved insightful. Becker and Murphy's (1988) famous approach boils addiction down to adjacent complementarities between current consumption and a "habit stock" based on past consumption. Their model allows some breathing room for investments to adjust the habit stock, such as deliberate time in rehab, and also allows shocks such as stressful events (divorce, unemployment) that could trigger "self-medicating" substance use. A richer model based on consumption states is Bernheim and Rangel (2004).

On another front, the neurobiology and clinical evidence indicates several interesting facts about the underlying mechanisms of addiction. Rats become biologically addicted, exhibiting tolerance and withdrawal, to all substances humans do, which implicates a common source in homologous rat and human brain areas. Many users exhibit polydrug use, substituting between drugs (perhaps very rationally in the sense of exhibiting high cross-price elasticity and sensitivity to full price effects like shifts in policing priority). A remarkable finding is that drug use habituates users to create homeostatic "feedforward" adaptation to environmental cues (like the time and place of habitual use). In plainer terms, suppose you regularly inject heroin with K.R. on Avenue C after 2 a.m. bar closing. Then seeing K.R., walking past Avenue C, or noticing that people are leaving bars that just closed could induce craving for the drug, as the body adjusts homeostatically for the expectation of imminent drug use. Laibson (2001) extends the rational choice model to include such cues.

Emotion: Thorough modeling of emotions has proved elusive in economics (though see Loewenstein 2000; Romer 2000; Loewenstein and O'Donoghue 2007). Some useful examples treat a particular emotion as a source of disutility and look for evidence of a negative emotion manifested in choice data (e.g., Costa and Kahn 2007). In psychological game theory (Dufwenberg 2008) and evolutionary psychology social emotions are thought to functionally signal surprises relative to expectations, and convey an expectation of future action. For example Sell, Tooby, and Cosmides (2009) define as an expression of disappointment in getting less from another person's action than was expected, which both invites an apology and threatens revenge.

Emotion is absent from Glimcher's book, and indeed, is also absent from much of decision neuroscience. An economicsfriendly view is that an emotion is a rapidlyprocessed reaction to good or bad news, felt by the body and expressed both externally (e.g., by facial expression, so other people can see) and internally (by the nervous system and brain circuitry). Adolphs described the modern view this way: ". . . emotions are triggered by events of some significance or relevance to an organism, that they encompass a coordinated set of changes in brain and body, and that they appear adaptive in the sense that they are directed towards coping with whatever challenge was posed by the triggering event" (2010).

In my view, economics should simply define an emotion as a distinct primitive concept that can have characteristics of utilities, 
information, or constraint. For example, fear feels unpleasant (people usually spend resources to avoid it), conveys noisy information about impending threat, and can reduce cognitive control and physical action (as in "paralyzed with fear").

Note also that there is no sharp divide between emotion and cognition; they are like Siamese twins. Top-down cognitive "reappraisal" influences emotions, and emotions influence information processing.

Incorporating emotion into economics is likely to be substantially aided by affective neuroscience. The neuroscience provides multiple biological measures of emotions, which are especially useful because any one measure-such as skin conductance-usually does not measure both the intensity of the emotion (arousal) and its "sign" (positive or negative "valence").

An example is two studies by SokolHessner et al. (2009) and Sokol-Hessner, Camerer, and Phelps (2013) on "emotional regulation" (also called "reappraisal") during risky choice. Their subjects made a series of choices between certain amounts and 50/50 gain-loss gambles (designed to estimate individual parameters of risk-aversion, loss-aversion, and response noise). They were trained to turn on and off a "cognitive re-appraisal," in blocks of 10 trials, which is intended to reduce negative emotion when taking a risk.

When subjects are "regulating" their negative emotions, their estimated loss-aversion is lower, and their skin conductance response to actually losing (when they do choose a gamble) is lower (Sokol-Hessner et al. 2009). Regulating subjects are changing revealed preferences by changing their emotions. fMRI analysis showed that DLPFC was active during regulation. Subjects who could regulate their loss response (as inferred from behavioral loss-aversion) showed reduced activity in the amygdala during loss (and no difference in gain).
How could we describe emotional regulation in economic terms? People have the capacity to imagine how they would feel and behave in different mental states (including emotional ones). Attention to the simulated state crowds out attention to the true state, which changes behavior and biological expression of emotion.

In fact, this sort of imagination is used routinely in life and in economics. One approach to acting is to imagine previous experiences that produce the emotion that is desired. For example, if you imagine how you would feel if your child died, you might feel genuine sadness. This doesn't mean that you "think" your child is dead; it just means you have the capacity to do counterfactual reasoning, and that reasoning can produce powerful emotions and can change behavior.

In economics, the ability to imagine what you might do in another state is essentially assumed in game theory when there are information asymmetries (e.g., a bidder must imagine what a bidder with a different value than their own will do, in an auction, unless he or she learned an equilibrium bidding function over time). So in economic language, we could translate the psychological concept of emotional regulation into "the use of scarce cognitive resources to self-create alternative states." Or we can just learn some new vocabulary-regulation, or reappraisal.

Social networks: A small literature is emerging showing a remarkable link between the extent of social networks, both across and within species. This is interesting as forming network links is a socio-economic choice, and networks are also institutions which can pass information and affect preference. The earliest finding is that, across primates and apes (including Homo sapiens), the relative size of the neocortex is monotonically related to the size of a typical everyday social group-for humans, our extra neocortex implies a group size of about 150 (Dunbar 1992). 
More surprisingly, new studies show that even within species, differences in brain volume in amygdala and cortex are associated with personal group size (Dunbar 2012; Bickart et al. 2011), and with monkey group size and dominance ranks (Sallet et al. 2011). None of these studies can clearly conclude whether brain structure supports large network interaction, or large networks grow brains. The crossspecies evidence suggests bigger brains subserve bigger networks, but general brain plasticity (in response to environment) also suggests that causality goes in both directions. It would be fascinating to examine brain structures and activity in people raised in unusually large or small groups (for exogeneous reasons) to help establish causality.

\section{Reviewing Foundations of Neuroeconomic Analysis}

As noted, the book is apparently not intended to be a comprehensive discussion of all of the methods and discoveries in neuroeconomics, as a handbook or textbook would strive to be. Instead, it is one part philosophy of knowledge, one part history of neuroscience, one part personal vision of a field, and one part NYU promotional brochure.

From the point of view of economists, the book's coverage and tone reflect two methodological convictions: first, that simple axiomatic systems which summarize the empirical implications (i.e., what axioms must be satisfied) of a class of functional representations should be central objects of study in neuroeconomics, and second, that neuroeconomics can most productively start by exploring whether neural circuitry implements simple rational choice.

\subsection{How Useful are Axioms?}

The view that axiomatic models will prove especially helpful in neuroeconomics is heavily promoted in Glimcher's book. ${ }^{2}$ Axiomatic systems summarize all the empirical choice restrictions a general class of models should satisfy, without typically specifying too precise a functional form. For example, expected utility theory axioms allow the utility function to have any shape, but require valuations to be sums of outcome utilities weighted linearly by their probabilities. If the independence axiom is systematically violated, then choices are not described by expected utilities.

The simplest example of how axiomatics could work in neuroscience is reward prediction error (RPE). RPE is the difference between a received reward and an expectation (an economic "surprise"). RPEs occur during learning, and mathematical adjustment to RPE can lead to good long-run learning properties (e.g., Sutton and Barto 1998).

RPEs have generally been measured as linear deviations between reward and expectations. Caplin et al. (2010) took a step back and suggested axioms defining a more general RPE structure. Define an RPE for outcome $x$ and expectation (or reference point) $r$ as $\delta(x, r)$. An axiomatic definition of an RPE is a function $\delta(x, r)$ which is increasing in $x$, decreasing in $r$, and which satisfies $\delta(x, r)=0$ when $x=r$ (i.e., the prediction error is zero when $\mathrm{x}$ is expected and received, regardless of the amount of reward $x$ ).

Many previous studies found evidence for RPE encoding based on a linear restriction $\delta(x, r)=x-r$, where $r(t)$ is an expectation or reference point that is tracked by reward history (typically with a decay or learning rate).

Caplin etal. (2010) cite these previous findings of linear RPE and conclude that "although generally supportive, these tests have all failed to be taken as conclusive proof of the DRPE hypothesis by assuming fixed values for the 'experienced reward' of

\footnotetext{
${ }^{2}$ See also Caplin and Dean (2008), and Dean (2013).
} 
different events and using a reinforcement learning model to construct a time path for 'predicted reward"' (p. 927). Basically, their planned contribution is to find RPE signals with a less parametric linear restriction.

However, their own analysis assumes fixed (cross-trial) values for experienced reward (by binning them according to equal outcomes) and assumes a fixed predicted reward based on stated probabilities, rather than predictions adjusted along a time path. Thus, even though their axiomatic system is more general, in principle, than the linear version, in execution it makes strong assumptions that reward expectation is constant.

The main point here is that both earlier analyses and their analysis must assume some auxiliary hypothesis about stability of reward values across trials, and some source of predictions. Why is one maintained hypothesis, then, more "conclusive proof" than another? The key difference is simply that the Caplin et al. (2010) analysis requires monotonicity but allows nonlinearity in the response to reward and prediction, and allows crosspartial effects of reward outcome on prediction. However, given that linearity is almost always an excellent approximation to a nonlinear monotonic function, this is a conceptually important distinction but not a practically important one. ${ }^{3}$ It is an incarnation of nonparametric versus parametric testing in which a parametric restriction is quite reasonable.

Figure 1 shows the BOLD signal from Rutiedge et al. (2010), with reward prediction on the $x$-axis. Figure 2 shows a comparable graph from Abler, who identified ROIs using an imposed linear contrast $\delta(x, r)=x-r=x-p x$. The Abler figures show strong support for the three general properties of DRPE axiomatically identified by Caplin and Dean: signals respond

\footnotetext{
${ }^{3}$ Abler et al. (2006) also tried a quadratic term using reward prediction error (RPE) but had no extra success, as the linear approximation fit well.
}

positively to reward, negatively to prediction, and the signal for getting either expected reward is the same. The only difference is that Abler imposes linearity and Caplin et al. (2010) allow nonlinearity (and fanning out of the two curves).

So let's take stock of what the axioms have added here. Axioms suggest that the strongest test is not what brain areas respond to linear $\delta(x, r)=x-r$, but instead what areas indicate positive and negative responses to $x$ and $r$, respectively, with $\delta(5,5)=\delta(-5,-5)=0$. Regions responsive to RPE identified by Abler et al. (2006) several years ago appear to pass these tests, visually. However, Abler et al. did not actually conduct the prescribed statistical tests; they impose linearized versions. So they got the right answer, but without statistical proof. Put differently, in this case the axioms point to more general tests about the shapes of BOLD response, but the linearized results are so compelling the contribution is not an empirical surprise, but instead is a useful methodological suggestion about how to do more careful statistical testing. $]^{4}$

Caplin et al. (2010) conclude that, "our work rigorously tests and confirms the conclusions of previous authors who have claimed to have found evidence in favor of the DRPE hypothesis in fMRI data." I agree that there is an added dimension of "rigor" from statistical testing of more general functional forms (response to $x$ and $r$ rather than linear response to $x-r$ ), but there is not a big leap in knowledge.

Furthermore, there are other neurometric dimensions of rigor and confirmation strength. For example, as Caplin et al. (2010) note, there are relatively few dopaminergic neurons in the brain (c. 105). Focusing on nucleus accumbens, which is known

\footnotetext{
4 Rutledge et al. (2010) uses the same data as Caplin et al. (2010) but explores the statistical testing of comparisons in multiple regions in a more thorough, powerful way.
} 


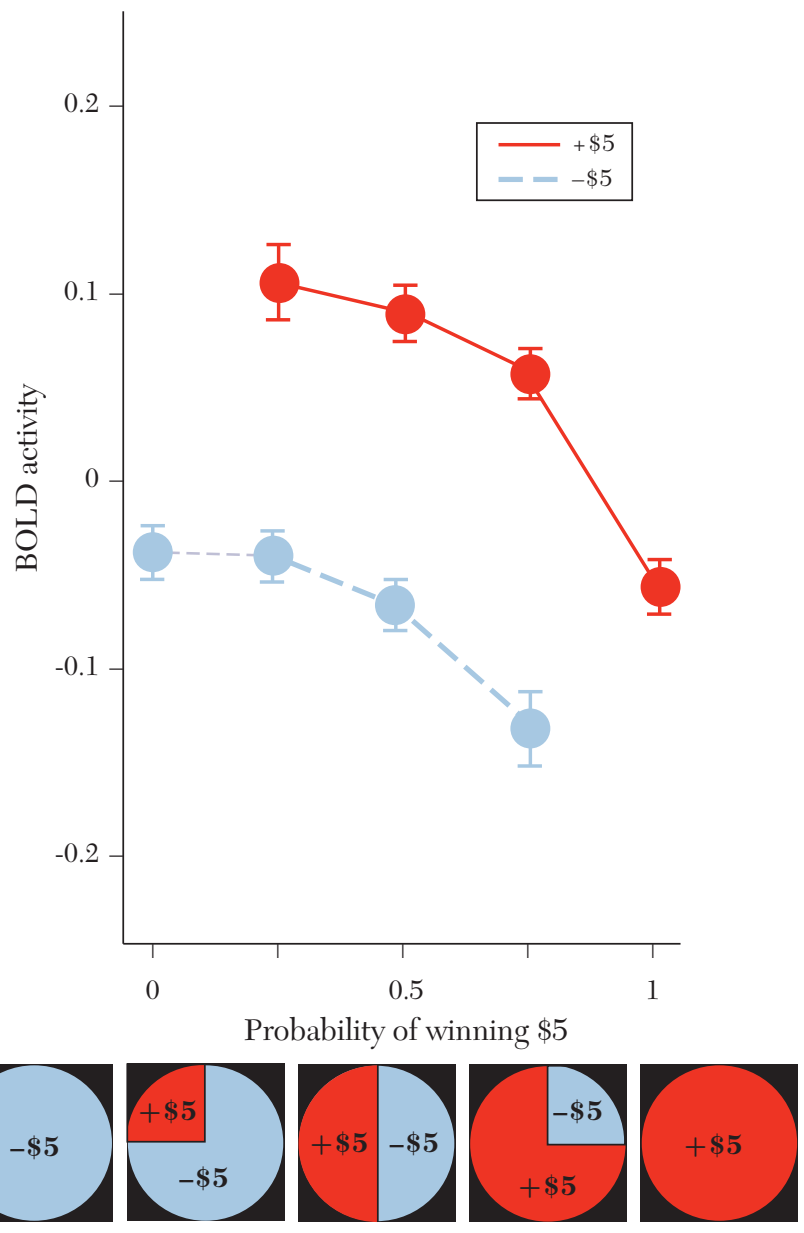

Figure 1. BOLD Activity in Response to Actually Winning or Losing $\$ 5$, Depending on the Probablility of Winning

Notes: Reward prediction errors should decline monotonically from left to right, be higher for wins $(\$ 5)$ than losses (-\$5) fixing probability, and the response to losing for sure (left point for $-\$ 5$ ) should be the same as winning for sure (right point for $\$ 5$ ). All these properties hold statistically.

Sources: Caplin et al. (2010). Reprinted with permission of the Journal of Neurophysiology.

to receive a large density of DA neurons, is then a reasonable choice. An even more conclusive approach, in one respect, is to record BOLD from areas that are known from single-unit electrode-based recordings to have an especially high density of DA neurons. Following this strategy, D’Ardenne et al. (2008) recorded BOLD from the small midbrain ventral tegmental area (VTA). The VTA was the original locus of recording by that ignited empirical study of prediction error (Schultz, Dayan, and Montague 1997). 

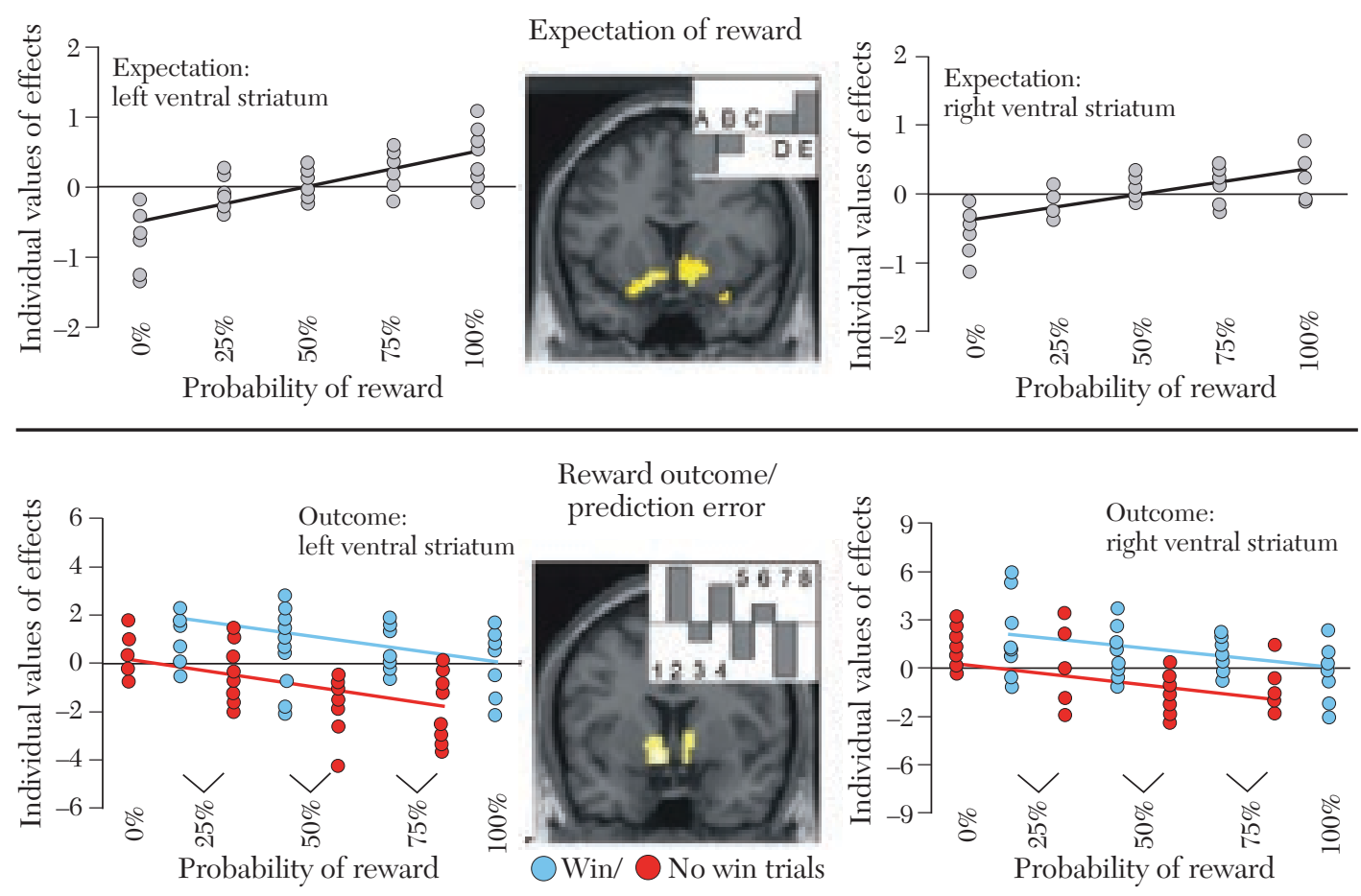

Figure 2. Bottom panel shows linear contrast of prediction error depending on known reward probability $(x$-axis $)$ and actual outcome (light $=$ win, dark $=$ loss $)$.

Note: Figure reprinted with permission of Neuroimage.

The VTA is small (only 2 voxels of typical $3 \times 3 \times 3 \mathrm{~mm}$ size) so they use a thinner slice and some improvements in methods-a different kind of rigor - to improve data quality. They find coarse evidence for DRPE in an area thought to be richer in DA neurons than NAcc (figure 3) Their data quality do not permit a statistically powerful test of the general Caplin et al. (2010) axioms. However, they have the advantage of finding evidence more tightly linked to where DA is actually transmitted.

Stepping back, how useful are axioms in neuroeconomics, and in general? First note that axioms can illuminate and clarify a good idea, but some good ideas also shine on their own. In economics, for a long time there was no axiomatic (epistemic) basis for Nash equilibrium (until Aumann and Brandenburger 1995). Informational efficiency of stock prices, a hypothesis which drove empirical finance for decades starting in 1965 with Gene Fama's dissertation, did not have clear formal basis until Grossman and Stiglitz (1980) showed, ironically, that full efficiency was implausible (if information is costly to gather). Gilboa et al. (2013) point out other examples.

It is notable that historically, important advances in axiomatization of choice models often come after empirical inspiration. This was certainly the case with Glimcher et al.'s work on RPE. It is also true in axiomatic work on preferences on menus, as illustrated by the many experimental examples described by Lipman and Pesendorfer (2013), which 
A

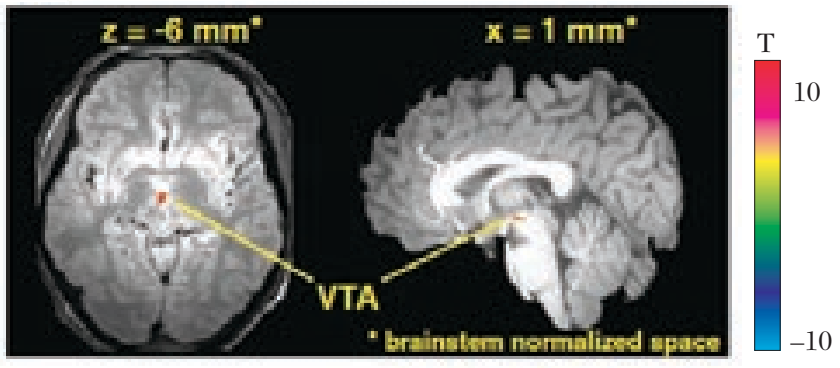

B

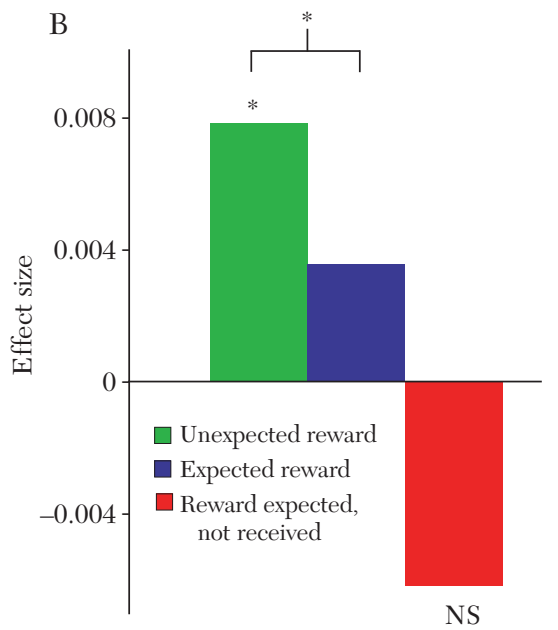

Figure 3. BOLD Response in Ventral Tegmental Area (VTA), Fine-Grained Imaging, in Response to Unexpected Reward Surprises

Notes: Results are not as strong in Caplin et al. (2010) and Abler et al. (2006), but image smaller regions of VTA known to be rich in dopamine receptors.

Source: D’Ardenne et al. (2008). Reprinted with permission of Science.

motivated axiomatics. Axiomatic systems are perhaps most useful at a middle stage of the data-theory-data cycle, showing the underlying ingredients are necessary and sufficient to account for a phenomenon, once the phenomenon is established. In this view, neural data might serve as inspiration for later modeling (Spiegler 2008). It could be that axiomatization will follow neural evidence, rather than lead it (as in the RPE case).

The alternative to an axiomatic or nonparametric approach is a workmanlike tinkering approach in which surprising effects are first generated (often absent any model at all), then parametric specifications are proposed and compared, and constant modification improves the models. ${ }^{5}$ Along

5 In tests of dopaminergic activity as encoding RPE, Caplin and Dean (2008, p. 26-27) note four potential these lines, Gilboa et al. (2013) propose a formal interpretation of axiomatic models as analogies. They note (p. 17) that an axiomatization cannot make a theory more true or false. Instead, "axiomatizations (in this case, of utility maximization) point out to us similarities that are not obvious a priori."

problems with nonaxiomatic parametric tests: 1) Tests require a joint hypothesis about RPE and rewards, beliefs and observables (but axiomatic tests do too); 2) parametric tests of one theory do not reject another poorly-specified theory (axiomatic tests don't either); 3) parametric tests may lack power to distinguish different functions (but general axioms have no distinguishing power at all by construction, and if distinction is sought it could be achieved, e.g., Hare et al. 2008); and 4) comparative "horse race" tests of specific theories do not give information about goodnessof-fit (that's wrong; they do). Thus, there is no special guarantee that tests of axioms are necessarily more conclusive than fitting specific functions in any of these four ways. 
Whether axioms or tinkering are better has something to do with scientific risk tastes. The axiomatic approach is safer, because choices will satisfy the axioms if any specific function within the class is correct. Conversely, if the axioms are clearly rejected, that could be bad news (less so in the analogy interpretation). While the rejections may offer guidance about how to weaken axioms, there may be a natural tendency to either object to the evidence or postpone for a long time the much harder work of finding weaker systems with plausible testable implications (as happened for many years after initial reports of the Allais and Ellsberg paradoxes). ${ }^{6}$

The tinkering approach is a bolder strategy, since a more specific functional form is more likely to be rejected. However, if a specific functional form passes strong tests, that is very good news. And a strong advantage of working with a specific functional form is that more precise predictions can be made about how much choices respond to changes, not simply the likely sign of a response.

With this example in mind, it is now useful to reflect on how promising axiomatic systems might prove to be in general.

Axiomatic systems are certainly useful in consolidating advancement of economic knowledge. However, the reliance on axiomatic systems to tie observable choice data to revelation unobservables is also the heart of the Gul-Pesendorfer assertion that nonchoice data are not needed.

In my view, axiomatic systems are likely to have a more limited role in neuroeconomics than Glimcher believes. To see why, consider how Spiegler (2013) describes the recipe for a particular popular axiomatic approach:

\footnotetext{
${ }^{6}$ Note that it took more than 20-30 years after the Allais paradoxes were pointed out for prospect theory and other formal non-EU systems to emerge. There was a similar lag from Ellsberg's 1961 paper on ambiguity-aversion to axiomatic systems.
}

According to "[David] Krepsian" methodology, one starts with an intuition or more systematic observations suggesting how a certain psychological "force" (ambiguity aversion, anxiety, desire for flexibility) might be connected to observed behavior, and one looks for a domain of choice objects (Anscombe-Aumann acts, temporal lotteries, menus), such that preferences over this domain could elicit this force.

The whole point of the modeling exercise is to identify the "force" by its impact on choice, without using any direct measure. However, the types of choice data needed to test these choice-based models get more and more complicated as the psychological force becomes more interesting. For example, in menu-based theories, the data needed are whether people choose over a wide variety of larger or smaller choice sets. What field settings supply these data?

Whether the original modelers like it or not, Krepsian analysis (as Spiegler describes it) certainly invites neuroeconomic "direct measure" of the hypothesized psychological forces because nonexperimental clear choices over menus might be rarely available. However, many-perhaps most-of the theorists working in this tradition seem to think the main value of the exercise is to avoid having to measure anything other than choices. But any particular axiomatic system is just one particular way of linking hypothesized forces with axioms and observable preferences. It would be an amazing coincidence if the axiomatic systems the Krepsian theorists produce happen to coincide with how the brain works (unless the axioms are proposed with brain knowledge in mind). There is hope for such coincidences, ${ }^{7}$ but I predict that the Krepsian program is not likely to produce many of them.

\footnotetext{
${ }^{7}$ A promising example is Fudenberg and Levine (2006), who clearly think of their short-run vs. long-run self model as having some neural plausibility.
} 
Finally, it is certainly true that the RPE axiomatics is a successful application because the axioms tell you clearly what to look for in the data ... and the data are easily available from an experiment (possibly even in a field setting).

\subsection{What is Most Authoritative and Convincing}

The core of the book, which is most authoritative, is building the empirical case for a two-stage model of simple choice: each object in a choice set is valued, then the values are compared and the best one is chosen (perhaps with stochastic choice about what's "best").

The neural evidence is compelling. Neural brain activity of different sorts-neural firing rates from single-unit recording, and BOLD signal from $\mathrm{fMRI}$ - is associated across many domains with expressed value ratings (on numerical scales) and with utilities inferred from decisions. This is an important step in showing that there are neutrally-derived numbers that correspond to behaviorallyderived numbers.

The evidence for a comparison process is not as clear. (Choice among four or more options, for example, has rarely been studied in decision neuroscience, to my knowledge).

There is much clear evidence of neurons implementing an optimal sequential probabilistic likelihood test (Gold and Shadlen 2007), OFC neurons that fire in response to comparative value (Padoa-Schioppa and Assad 2006), and cingulate activity in response to comparative value (e.g., Hsu et al. 2005).

Utility maximization over two choices works well because reinforcement learning systems do very well under environmental stability with rapid clear feedback. ${ }^{5}$ This fact

\footnotetext{
${ }^{8}$ My thesis advisors Einhorn and Hogarth (1978) made the important point that when feedback lags are not rapid,
}

was anticipated, in a sense, by Pareto who specifically thought of stable tastes as resulting from a trial-and-error learning process. ${ }^{9}$

The extrapolation from this well-documented process of learned simple valuation to more complex lifelike choices will be much more challenging. In this sense, Foundations documents the current solution to the easiest problem, to show economists what part of a good neuroeconomic foundation looks like, but leaves the bigger challenges for the future.

There are many kinds of evidence and nascent theories (some going back decades) showing when the simple value-then-compare does not seem to apply, including:

- Choices among several objects with multiple attributes, in which important attributes are often used to screen out poor choices (Tversky 1972);

- A shift from decision rules using more information to rules using less information as choice complexity increases (Payne, Bettman, and Johnson 1993);

- Regret theories in which the sign of the comparative value of choices $A$ and $B, \psi(A, B)$, determines choice ( $A$ is preferred if $\psi(A, B)>0$ ) (Loomes and Sugden 1987). In this theory there is not necessarily an initial valuation of choice objects separately;

and are noisy, learning degrades badly. These conditions have not been studied in human decision neuroscience.

9 Pareto (1971) wrote: "A man who buys a certain food for the first time may buy more of it than is necessary to satisfy his tastes, price taken into account. But in a second purchase he will correct his error, in part at least, and thus, little by little, will end up by procuring exactly what he needs. We will examine this action at the time when he has reached this state. Similarly, if at first he makes a mistake in his reasoning about what he desires, he will rectify it in repeating the reasoning and will end up by making it completely logical. (Ch. 3, \$1)" Bruni and Sugden (2007) give a wonderful description of this point and the ongoing debates surrounding it during the rise of neoclassical economics. 
- Effects of irrelevant alternatives or choice context (also called menu effects) on individual valuation or comparison of choices (e.g., Soltani, De Martino, and Camerer 2012);

- Choices from lists (Rubinstein and Salant 2006) and satisficing (Caplin, Dean, and Martin 2011) (not all objects are valued).

\section{Highs and Lows in Foundations of Neuroeconomic Analysis}

\subsection{Highlights}

Glimcher is a careful and extraordinarily clear writer. There are many gems. For example, Glimcher notes that "[a]t its inception WARP defined a minimalist esthetic that dominates economics to this day. How little can you assume in your model and how much can it prove?" (p 57).

This compelling passage also shows why (most) psychologists dislike economic modeling-the models have "too little" in them! Of course, for economists that is precisely the point, and the source of such models' charm and power.

Range normalization: The simple valueand-compare model is most vulnerable in comparing choices across choice sets. The reason is that increases in the range of stimulus attributes lead to local divisive normalization (also called "range adaption"). This general phenomenon has been well known for about thirty years, in behavioral economics in the form of context- (or menu-) dependence (Huber, Payne, and Puto 1982) and was precisely modeled starting in 1992 for visual cortical neurons (Heeger 1992; Carandini, Heeger, and Movshon 1997); and see Padoa-Schioppa (2009) for rangedependent value encoding in OFC. This property can clearly violate independence of irrelevant alternatives (IIA) in choice, since an irrelevant (unchosen, low-value) alternative can change the ranges and deform normalized subjective values of other choice objects.

Context-dependent choice has been observed in many species besides humans, including honeybees, gray jays (Shafir, Waite, and Smith 2002) and slime molds (Latty and Beekman 2011). The species-generality of these effects suggest that if there is a single explanation of context effects, it is a lowlevel sensory normalization, rather than a sophisticated explanation, which does not apply to slime molds (e.g., Kamenica 2008). Privileging a low-level explanation immediately invites a careful look at basic neuroscience, in which normalization is common in sensory systems and is therefore best understood at low levels.

There is a deep, important discussion of neural normalization in chapter 10, and its implications for economics (much based on an important paper by Louie, Grattan, and Glimcher 2011). The main intuitive point they draw out is that as choice sets grow larger, normalization means that the (normalized) subjective value of the best and nearly-best options will fall. This effect will create more choice "errors" (or random-utility-based reversals), lower choice satisfaction (if satisfaction if driven by relative comparisons), and possibly choice postponement (if there is a choice threshold that no single choice can reach).

The book ends with a nice string of firecracker explosions.

Chapter 14 is wonderful. It organizes material around region-by-region evidence of how five brain regions are active during aspects of subjective valuation. This is meant to be the best available answer to "Why care about where?" The general answer is that, if a region appears to make two different computations that were not thought to be related in current theory, that finding suggests a need to have a theory linking those computations. 
Chapter 16 collects the formalisms developed earlier in one place. Economists who confuse math-free psychology and computational neuroscience should read this chapter over and over, and assign it to students. It contains much of the formalism that will propel decision neuroscience for the next 10 years. An action-packed picture accompanying this grand vision is reproduced in figure 4, showing how economic, psychological, and neuroscientific analyses can be linked from high level (behavioral) to low level (mechanistic).

The last chapter, 17 , is a perfect ending to the book. The chapter poses six unanswered questions. Every graduate student or newcomer to this field should read this list (as well as Huettel 2010). A more ambitious list could be constructed, but Glimcher's compact six-point plan gives us plenty to do.

\subsection{Lowlights}

There are some things to disagree about in the book. The substantive areas undoubtedly reflect the author's idiosyncratic beliefs about intellectual contributions, history, and directions (chiefly, discussions of prospect theory). Some other debatable material, in my view as a long-standing contributor to the field, reflects a misunderstanding about behavioral economics or simply repeats criticisms that have been addressed early and often. Chapter 15, titled "Beyond Neoclassics: Behavioral Neuroeconomics," is weak. It features an intriguing discussion of hierarchical "editing" (which deeply undercuts extending the value-compare model beyond 2-choice sets), but no data.

For example, Glimcher writes that "Kahneman and Tversky provided almost no information about how the reference point was to be determined ...." Actually, Kahneman and Tversky wrote:

An essential feature of the present theory is that the carriers of value are changes in wealth or welfare, rather than final states. This assumption is compatible with basic principles of perception and judgment. Our perceptual apparatus is attuned to the evaluation of changes or differences rather than to the evaluation of absolute magnitudes. When we respond to attributes such as brightness, loudness, or temperature, the past and present context of experience defines an adaptation level, or reference point, and stimuli are perceived in relation to this reference point. Thus, an object at a given temperature may be experienced as hot or cold to the touch depending on the temperature to which one has adapted. The same principle applies to non-sensory attributes such as health, prestige, and wealth. The same level of wealth, for example, may imply abject poverty for one person and great riches for another-depending on their current assets. (p 277)

Thus, Kahneman and Tversky clearly state that the reference point is "the past and present context of experience" and give examples of what that means. It's true they do not provide "information" (i.e., data), but there is plenty of inspiration.

Glimcher (p. 294) lauds the step forward by Koszegi and Rabin (2006), who focus on "recent expectations" about likely outcomes as reference points. However, Kahneman and Tversky clearly anticipated this insight, noting that the status quo is not always the natural reference point. They wrote:

Although this is probably true for most choice problems, there are situations in which gains and losses are coded relative to an expectation or aspiration level that differs from the status quo. For example, an unexpected tax withdrawal from a monthly pay check is experienced as a loss, not as a reduced gain. Similarly, an entrepreneur who is weathering a slump with greater success than his competitors may interpret a small loss as a gain, relative to the larger loss he had reason to expect. (p 286)

This Kahneman and Tversky passage clearly shined a flashlight in the direction of expectations rather than status quo. (Kahneman 1992 also wrote about mixtures of reference points in a largely-overlooked paper that is insightful). 


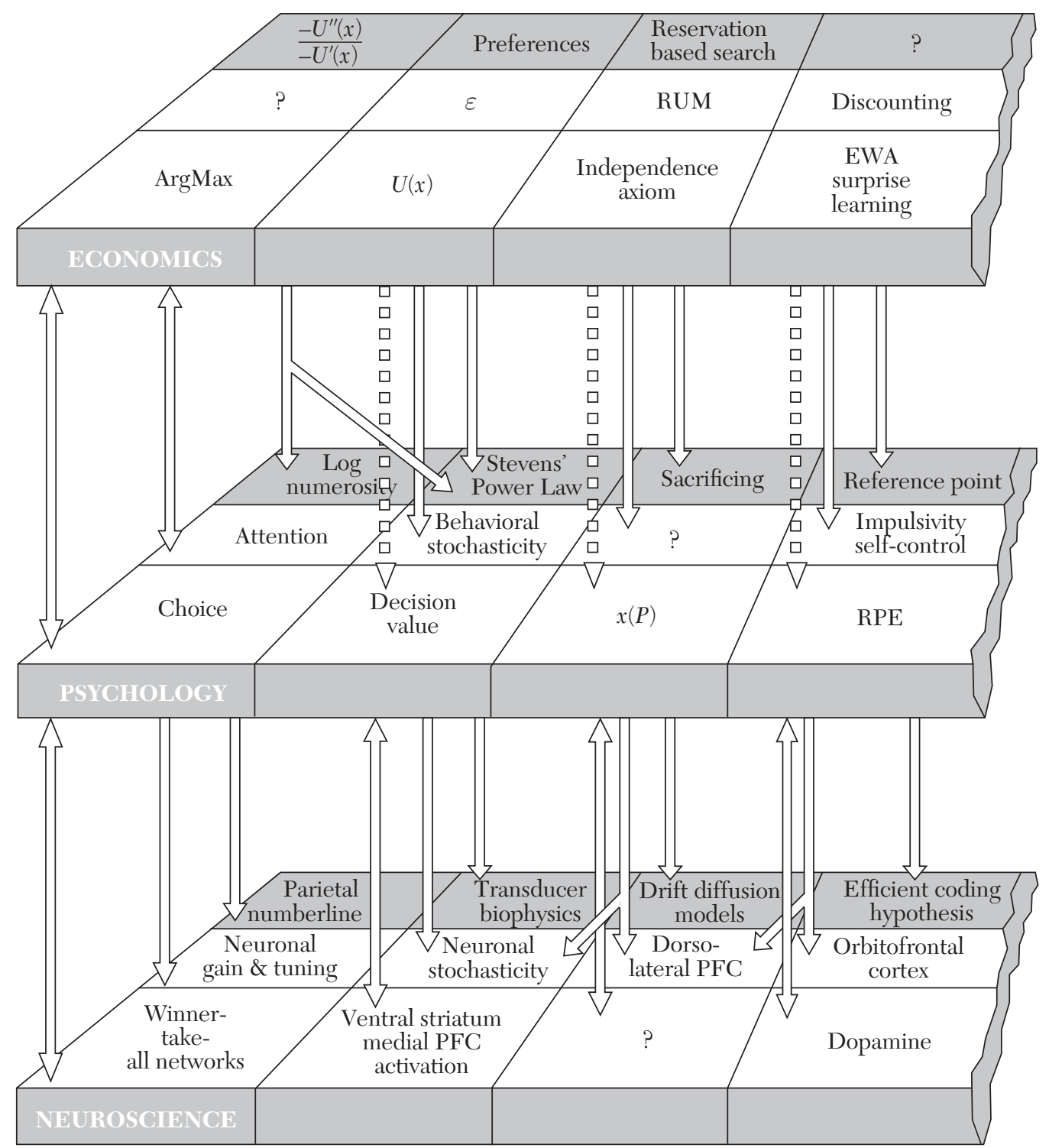

Figure 4. Schematic Showing Correspondence of Economic (Behavioral), Psychological, and Neuroscientific Concepts

Source: Glimcher (2011). Figure courtesy of the author. 
Glimcher goes further in making bold claims: "What we can see from this neuroeconomic analysis, however, is that these local irrationalities [reference-dependencies] arise because evolution is trading off the costs of accurate sensory encoding against the costs of irrational decision making."

Of course, the neuroeconomics per se does not show any clear evidence of an evolutionary tradeoff. Proving that evolutionary selection led to a particular kind of neural architecture for tradeoff is extraordinarily difficult. The evidence just shows that relative coding is pervasive and absolute coding is not. There is no evidence from the neuroscience, per se, that the degree of reference-dependence seen in modern human experiments is a clear product of an evolutionary tradeoff. I think that hypothesis is likely to be true in many respects, but it has not been tested directly; doing so is an exciting (and difficult) challenge for future work.

Glimcher gets a little carried away in some other passages (as enthusiastic authors can do). He says that normalization "may provide the central tool for fully cardinalizing utility" (p. 241, fn 10). He also thinks "the baseline level of activation measured by the scanner - the unique zero point-is the physical instantiation of the reference point...this finding also provides us with an empirical tool for rendering the [expectational] reference point directly observable" (p. 354).

\subsection{Oops: Style and Curious Emphases}

There are some notable stylistic features of the choice of what material to emphasize that I found strange or objectionable. These choices are a book writer's prerogative; and reacting to them is also a reader's prerogative.

First: The title!? The name is presumably an homage to Samuelson's aptly-named Foundations of Economic Analysis. Naming a book after such a seminal classic invites a comparison that an author should not want readers to make. The homage title also misses the essence of Samuelson's book, which is a pathbreaking mathematical analysis of economic systems, not just a useful model of individual behavior.

The book is also packed with the loudest cheers when the home team (NYU) scores. Remember the famous 1976 Saul Steinberg "New Yorker" cover? It depicted a distorted map looking west from 9th avenue in Manhattan. The cartoon showed detailed pedestrians, buildings and cars from the East River up to 10th avenue, then a thin strip of "Jersey" past the wide Hudson River, and a modest patch representing the entire rest of the United States.

This book is akin to a Saul Steinberg cartoon from a NYU-roeconomic perspective. Some of the pro-NYU attention is justified, but the emphasis is heavy and uneven. Besides Glimcher's own work, the work and collaborations with Andrew Caplin (NYU) get special attention and explanation, as does an influential mathematical normalization of visual cortex responses proposed David Heeger (1992). A normalization of neural inputs due to Schwartz and Simoncelli (2001) (one of several in the literature) is ushered onstage as the "Schwartz-Simoncelli" equation.

However, other local NYU contributions to neuroeconomics are surprisingly absent. NYU cognitive neuroscientist Elizabeth Phelps collaborated with NYU economist Andrew Schotter and others (Delgado et al. 2008) to show how fMRI activity during overbidding in auctions suggested a kind of endowment effect from "losing" an auction one was expecting to win. The neural evidence suggested a novel prediction about how economically identical auctions would lead to different bids, a prediction they confirmed. Using neural evidence to predict novel, surprising institutional effects is something economists are keenly interested in, so it is unfortunate that was not discussed at all in the book. 
Contributions of other neuroeconomists outside of Manhattan below 14th Street are also omitted. Greg Berns, Giorgio Coricelli, Mauricio Delgado, Ernst Fehr, Kevin McCabe, Aldo Rustichini, and Paul Zak might be disappointed to see their names missing entirely. Ray Dolan, Read Montague, and Sam McClure are cited once each. Among past presidents of the Society for Neuroeconomics (excluding Paul Glimcher, his former postdoc Michael Platt, and Manhattanites), there are no citations at all of work by Peter Bossaerts, Hauke Heekeren, and Scott Huettel, two for myself, and five for Antonio Rangel. Meanwhile, Oskar Morgenstern is cited six times, and neuroskeptic Faruk Gul is cited nine times.

There is a lot of Nobel-associated name checking. Readers are pointed toward Nobel Laureate Selten's (1975) paper on trembling-hand perfection for an "excellent description" of random utility stochasticity as a series of choice errors. (Selten's main idea, actually, was to use the device of (vanishing) errors to allow Bayesian updating at non-equilibrium nodes, not especially to introduce stochastic choice or even to model choice error in a biologically plausible way.) We are also told that Nobel Laureate Dan McFadden (1974) developed probabilistic choice modeling after being "struck by this logic, and how it differed from signal detection theory." Actually, he cites Thurstone (1927) on psychophysical error and has nothing to say about signal detection (see McFadden 2001).

Some of the history and descriptions of behavioral economics developments are just wrong or curiously reconstructed. Glimcher traces a path from responding to the (Nobel Laureate) Allais paradox by abandoning the mathematical-axiomatic approach in favor of the "contemporary 'heuristics and biases' approach" (e.g., Tversky and Kahneman 1974; Kahneman, Slovic, and Tversky 1982).
That's not how it happened (see Kahneman and Tversky 1982).

He says that Kahneman and Tversky got reference dependence by "borrowing from earlier neoclassical writers" (p. 287). But Markowitz (1952) is the only one Kahneman and Tversky cited in their seminal 1979 paper, and they noted other empirical studies showing reflection of gain-loss risk attitudes, but not from neoclassicals. Tversky and Kahneman (1981) further clarify that their inspiration came largely from figureground perceptual switches familiar from visual cognitive science, not from a small branch of neoclassical thinking.

Glimcher also "hastens to point out that many features of the 'Asian disease problem' [which demonstrates reflection effects] have limited its impact in economic circles," allegedly because it is artificial ("make-believe"), low-stakes, possibly conveys information, and is perhaps confusing. All these nuisance critiques have been ruled out many times early (and late, too) in the history of behavioral economics experiments. Furthermore, Laibson and Zeckhauser (1998, table 2) show from citations that the framing examples in their 1981 paper, and later papers using the same ideas, actually did have substantial impact in top economics journals.

A description of how endowment affects how experiments are run is a pastiche of the methods that have actually been used (pp. 105-06), like a Hollywood screen writer's "composite character." We are also told (p. 384) that Hertwig et al. (2004) estimated a probability weighting function. They did not.

The sourcing is missing or sketchy in important passages about how psychology and economic theory have interacted historically. Incomplete sourcing can especially distract people in a rapidly-emerging interdisciplinary field for two reasons: fevered criticism may be quickly refuted (or may have been refuted already, but is unknown 
to critics); and paying attention to the most shrill critics can lead to tyranny of a vocal minority. Here are two examples, of the sort that a New Yorker-quality fact checker would have noted:

- “... before Allais' paradox was discovered, there was an almost universal conviction that axioms rooted in expected utility theory would successfully describe human choice behavior."

- "... ga group of psychologists and neurobiologists have argued that even the phrase 'neuroeconomics' is distasteful because of its obvious ties to what Carlyle (1849) called 'the dismal science."”

\section{Conclusion}

Paul Glimcher's book makes a strong, coherent, empirical argument for the potential of neural measures of subjective value to match up to, and potentially inform, the simplest economic concepts and questions. His approach is patient and conservative, in the sense that he adheres to a style-rooted in rational choice, moving cautiously, and endorsing axiomatic systems as a method to efficiently test families of potential behavioral functional forms-which economists will be most comfortable with. I prefer to rush ahead using what is known from a few decades of behavioral economics to begin looking for neural circuits that adjudicate between rational and behavioral models (often alternative models, which proliferate quickly since economists are so good at theorizing from sparse data) or which break new ground. Happily, these slow and fast approaches can both be pursued in parallel, and they are.

\section{REFERENCES}

- Abler, Birgit, Henrik Walter, Susanne Erk, Hannes Kammerer, and Manfred Spitzer. 2006. "Prediction Error as a Linear Function of Reward Probability is Coded in Human Nucleus Accumbens." NeuroImage 31 (2): 790-95.

-Adolphs, Ralph. 2010. "Emotion." Current Biology 20
(13): R549-52.

-Aumann, Robert, and Adam Brandenburger. 1995. "Epistemic Conditions for Nash Equilibrium." Econometrica 63 (5): 1161-80.

-Becker, Gary S., and Kevin M. Murphy. 1988. "A Theory of Rational Addiction." Journal of Political Economy 96 (4): 675-700.

-Bernheim, B. Douglas. 2009. "On the Potential of Neuroeconomics: A Critical (but Hopeful) Appraisal.” American Economic Journal: Microeconomics 1 (2): 1-41.

Bernheim, B. Douglas, and Antonio Rangel. 1994. "Addiction and Cue-Triggered Decision Processes." American Economic Review 94 (5): 1558-90.

-Berns, Gregory, Jonathan Chappelow, Milos Cekic, Caroline F. Zink, Giuseppe Pagnoni, and Megan E. Martin-Skurski. 2006. "Neurobiological Substrates of Dread.” Science 312 (5774): 754-58.

Berridge, Kent C., and John P. O’Doherty. 2014. "From Expected Utility to Decision Utility." In Neuroeconomics: Decision Making and the Brain, Second edition, edited by Paul W. Glimcher and Ernst Fehr, 335-54. London and San Diego: Elsevier: Academic Press.

Bhatt, Meghana A., Terry Lohrenz, Colin F. Camerer, and P. Read Montague. 2010. "Neural Signatures of Strategic Types in a Two-Person Bargaining Game." Proceedings of the National Academy of Sciences 107 (46): 19720-25.

Bhatt, Meghana A., Terry Lohrenz, Colin F. Camerer, and P. Read Montague. Forthcoming. "Distinct Contributions of the Amygdala and Parahippocampal Gyrus to Suspicion in a Repeated Bargaining Game.” Proceedings of the National Academy of Sciences.

-Bickart, Kevin C., Christopher I. Wright, Rebecca J. Dautoff, Bradford C. Dickerson, and Lisa Feldman Barrett. 2011. "Amygdala Volume and Social Network Size in Humans." Nature Neuroscience 14 (2): 163-64.

-Bruni, Luigino, and Robert Sugden. 2007. "The Road Not Taken: How Psychology Was Removed from Economics, and How It Might Be Brought Back." Economic Journal 117 (516): 146-73.

-Camerer, Colin F., and Teck-Hua Ho. 1999. "Experience-Weighted Attraction Learning in Normal Form Games." Econometrica 67 (4): 827-74.

-Camerer, Colin F., Teck-Hua Ho, and Juin-Kuan Chong. 2004. "A Cognitive Hierarchy Model of Games." Quarterly Journal of Economics 119 (3): 861-98.

Camerer, Colin F., and Alec Smith. 2012. "Cognitive Hierarchies and Emotions in Behavioral Game Theory." In Oxford Handbook of Thinking and Reasoning, edited by Keith J. Holyoak and Robert G. Morrison, 346-63. Oxford and New York: Oxford University Press.

Camille, Nathalie, Cathryn A. Griffiths, Khoi Vo, Lesley K. Fellows, and Joseph W. Kable. 2011. "Ventromedial Frontal Lobe Damage Disrupts Value Maximization in Humans." Journal of Neuroscience 31 (20): 7527-32. 
Caplin, Andrew, and Mark Dean. 2008. "Axiomatic Neuroeconomics." In Neuroeconomics: Decision Making and the Brain, edited by Paul W. Glimcher, Colin F. Camerer, Ernst Fehr, and Russell A. Poldrack, 21-32. London and San Diego: Elsevier, Academic Press.

Caplin, Andrew, Mark Dean, Paul W. Glimcher, and Robb B. Rutledge. 2010. "Measuring Beliefs and Rewards: A Neuroeconomic Approach." Quarterly Journal of Economics 125 (3): 923-60.

-Caplin, Andrew, Mark Dean, and Daniel Martin. 2011. "Search and Satisficing." American Economic Review 101 (7): 2899-2922.

-Caplin, Andrew, and John Leahy. 2001. "Psychological Expected Utility Theory and Anticipatory Feelings." Quarterly Journal of Economics 116 (1): 55-79.

Carandini, Matteo, David J. Heeger, and J. Anthony Movshon. 1997. "Linearity and Normalization in Simple Cells of the Macaque Primary Visual Cortex." Journal of Neuroscience 17 (21): 8621-44.

Carlyle, Thomas. 1849. "Occasional Discourse on the Negro Question." Fraser's Magazine for Town and Country 40.

-Carter, R. McKell, Justin R. Meyer, and Scott A. Huettel. 2010. "Functional Neuroimaging of Intertemporal Choice Models: A Review." Journal of Neuroscience, Psychology, and Economics 3 (1): 27-45.

-Casey, B. J., Sarah Getz, and Adriana Galvan. 2008. "The Adolescent Brain." Developmental Review 28 (1): $62-77$.

-Chen, M. Keith, Venkat Lakshminarayanan, and Laurie R. Santos. 2006. "How Basic Are Behavioral Biases? Evidence from Capuchin Monkey Trading Behavior." Journal of Political Economy 114 (3): 517-37.

-Chib, Vikram S., Benedetto De Martino, Shinsuke Shimojo, and John P. O’Doherty. 2012. "Neural Mechanisms Underlying Paradoxical Performance for Monetary Incentives Are Driven By Loss Aversion." Neuron 74 (3): 582-94.

-Colander, David. 2007. "Edgeworth's Hedonimeter and the Quest to Measure Utility: Retrospectives." Journal of Economic Perspectives 21 (2): 215-25.

Coricelli, Giorgio, and Rosemarie Nagel. 2009. "Neural Correlates of Depth of Strategic Reasoning in Medial Prefrontal Cortex." Proceedings of the National Academy of Sciences 106 (23): 9163-68.

-Costa, Dora L., and Matthew E. Kahn. 2007. "Deserters, Social Norms, and Migration." Journal of Law and Economics 50 (2): 323-53.

-Crawford, Vincent P., Miguel A. Costa-Gomes, and Nagore Iriberri. 2013. "Structural Models of Nonequilibrium Strategic Thinking: Theory, Evidence, and Applications." Journal of Economic Literature 51 (1): 5-62.

D'Ardenne, Kimberlee, Samuel M. McClure, Leigh E. Nystrom, and Jonathan D. Cohen. 2008. "BOLD Responses Reflecting Dopaminergic Signals in the Human Ventral Tegmental Area." Science 319 (5867): 1264-67.

Dean, Mark. 2013. "What Can Neuroeconomics Tell Us About Economics (and Vice Versa).” In Comparative
Decision Making, edited by Philip H. Crowley and Thomas R. Zentall, 163-203. Oxford and New York: Oxford University Press.

-Delgado, Mauricio R., Andrew Schotter, Erkut Y. Ozbay, and Elizabeth A. Phelps. 2008. "Understanding Overbidding: Using the Neural Circuitry of Reward to Design Economic Auctions." Science 321 (5897): 1849-52.

De Martino, Benedetto, Colin F. Camerer, and Ralph Adolphs. 2010. "Amygdala Damage Eliminates Monetary Loss Aversion." Proceedings of the National Academy of Sciences 107 (8): 3788-92.

-De Martino, Benedetto, Dharshan Kumaran, Ben Seymour, and Raymond J. Dolan. 2006. "Frames, Biases, and Rational Decision-Making in the Human Brain." Science 313 (5787): 684-87.

-De Martino, Benedetto, John P. O’Doherty, Debajyoti Ray, Peter Bossaerts, and Colin F. Camerer. 2013. "In the Mind of the Market: Theory of Mind Biases Value Computation during Financial Bubbles.” Neuron 79 (6): 1222-31.

Dufwenberg, Martin. 2008. "Psychological Games." In The New Palgrave Dictionary of Economics, Second edition, edited by Steven N. Durlauf and Lawrence E. Blume, 714-18. New York: Palgrave Macmillan.

Dunbar, Robin I. M. 1992. "Neocortex Size as a Constraint on Group Size in Primates." Journal of Human Evolution 22 (6): 469-93.

Dunbar, Robin I. M. 2012. "The Social Brain Meets Neuroimaging." Trends in Cognitive Sciences 16 (2): 101-02.

Einhorn, Hillel J., and Robin M. Hogarth. 1978. "Confidence in Judgment: Persistence of the Illusion of Validity." Psychological Review 85 (5): 395-416.

-Ellsberg, Daniel. 1961. "Risk, Ambiguity, and the Savage Axioms." Quarterly Journal of Economics 75 (4): 643-69.

Falk, Emily B., Elliot T. Berkman, and Matthew D. Lieberman. 2012. "From Neural Responses to Population Behavior: Neural Focus Group Predicts Population-Level Media Effects." Psychological Science 23 (5): 439-45.

Falk, Emily B., Elliot T. Berkman, Danielle Whalen, and Matthew D. Lieberman. 2011. "Neural Activity during Health Messaging Predicts Reductions in Smoking Above and Beyond Self-Report." Health Psychology 30 (2): 177-85.

-Falk, Emily B. Sylvia A. Morelli, B. Locke Welborn, Karl Dambacher, and Matthew D. Lieberman. 2013. "Creating Buzz: The Neural Correlates of Effective Message Propagation.” Psychological Science 24 (7): 1234-42.

-Fama, Eugene F. 1965. "The Behavior of Stock-Market Prices." Journal of Business 38: 34-105.

-Farroni, Teresa, Gergely Csibra, Francesca Simion, and Mark H. Johnson. 2002. "Eye Contact Detection in Humans from Birth." Proceedings of the National Academy of Sciences 99 (14): 9602-05.

-Farroni, Teresa, Mark H. Johnson, Enrica Menon, Luisa Zulian, Dino Faraguna, and Gergely Csibra. 2005. "Newborns' Preference for Face-Relevant Stimuli: 
Effects of Contrast Polarity." Proceedings of the National Academy of Sciences 102 (47): 17245-250.

-Fehr, Ernst, and Colin F. Camerer. 2007. "Social Neuroeconomics: The Neural Circuitry of Social Preferences." Trends in Cognitive Sciences 11 (10): 419-27.

-Figner, Bernd, et al. 2010. "Lateral Prefrontal Cortex and Self-Control in Intertemporal Choice." Nature Neuroscience 13 (5): 538-39.

Fox, Craig R., and Liat Hadar. 2006. “Decisions from Experience' $=$ Sampling Error + Prospect Theory: Reconsidering Hertwig, Barron, Weber \& Erev (2004)." Judgment and Decision Making 1 (2): 159-61.

-Fudenberg, Drew, and David K. Levine. 2006. “A Dual-Self Model of Impulse Control." American Economic Review 96 (5): 1449-76.

Gilboa, Itzhak, Andrew Postlewaite, Larry Samuelson, and David Schmeidler. 2013. "Economic Models as Analogies." http:/itzhakgilboa.weebly.com/ uploads/8/3/6/3/8363317/gpss_economic_models_ as_analogies.pdf.

-Glimcher, Paul W., and Aldo Rustichini. 2004. "Neuroeconomics: The Consilience of Brain and Decision." Science 306 (5695): 447-52.

-Gold, Joshua I., and Michael N. Shadlen. 2007. "The Neural Basis of Decision Making." Annual Review of Neuroscience 30: 535-74.

Grossman, Sanford J., and Joseph E. Stiglitz. 1980. “On the Impossibility of Informationally Efficient Markets." American Economic Review 70 (3): 393-408.

Gul, Faruk, and Wolfgang Pesendorfer. 2008. "The Case for Mindless Economics." In The Foundations of Positive and Normative Economics: A Handbook, edited by Andrew Caplin and Andrew Schotter, 3-42. Oxford and New York: Oxford University Press.

-Hampton, Alan N., Peter Bossaerts, and John P. O’Doherty. 2008. "Neural Correlates of MentalizingRelated Computations during Strategic Interactions in Humans." Proceedings of the National Academy of Sciences 105 (18): 6741-46.

-Harbaugh, William T., Ulrich Mayr, and Daniel R. Burghart. 2007. "Neural Responses to Taxation and Voluntary Giving Reveal Motives for Charitable Donations." Science 316 (5831): 1622-25.

- Hare, Todd A., Colin F. Camerer, and Antonio Rangel. 2009. "Self-Control in Decision-Making Involves Modulation of the vmPFC Valuation System." Science 324 (5927): 646-48.

-Hare, Todd A., John O'Doherty, Colin F. Camerer, Wolfram Schultz, and Antonio Rangel. 2008. "Dissociating the Role of the Orbitofrontal Cortex and the Striatum in the Computation of Goal Values and Prediction Errors." Journal of Neuroscience 28 (22): 5623-30.

-Heeger, David J. 1992. "Normalization of Cell Responses in Cat Striate Cortex." Visual Neuroscience 9 (2): 181-97.

Hershfield, Hal E., et al. 2011. "Increasing Saving Behavior through Age-Progressed Renderings of the Future Self." Journal of Marketing Research (Special Issue): S23-37.
-Hertwig, Ralph, Greg Barron, Elke U. Weber, and Ido Erev. 2004. "Decisions from Experience and the Effect of Rare Events in Risky Choice." Psychological Science 15 (8): 534-39.

Hertwig, Ralph, Greg Barron, Elke U. Weber, and Ido Erev. 2005. "The Role of Information Sampling in Risky Choice." In Information Sampling and Adaptive Cognition, edited by Klaus Fiedler and Peter Juslin, 72-91. Cambridge and New York: Cambridge University Press.

-Hsu, Ming, Meghana Bhatt, Ralph Adolphs, Daniel Tranel, and Colin F. Camerer. 2005. "Neural Systems Responding to Degrees of Uncertainty in Human Decision-Making." Science 310 (5754): 1680-83.

-Hsu, Ming, Ian Krajbich, Chen Zhao, and Colin F. Camerer. 2009. "Neural Response to Reward Anticipation under Risk Is Nonlinear in Probabilities." Journal of Neuroscience 29 (7): 2231-37.

-Huber, Joel, John W. Payne, and Christopher Puto. 1982. "Adding Asymmetrically Dominated Alternatives: Violations of Regularity and the Similarity Hypothesis." Journal of Consumer Research 9 (1): 90-98.

Huettel, Scott A. 2010. “Ten Challenges for Decision Neuroscience." Frontiers in Neuroscience 4: 171.

-Izuma, Keise, Kenji Matsumoto, Colin F. Camerer, and Ralph Adolphs. 2011. "Insensitivity to Social Reputation in Autism." Proceedings of the National Academy of Sciences 108 (42): 17302-07.

-Izuma, Keise, Daisuke N. Saito, and Norihiro Sadato. 2010. "Processing of the Incentive for Social Approval in the Ventral Striatum during the Charitable Donation." Journal of Cognitive Neuroscience 22 (4): 621-31.

- Jessup, Ryan K., Anthony J. Bishara, and Jerome R. Busemeyer. 2008. "Feedback Produces Divergence from Prospect Theory in Descriptive Choice." Psychological Science 19 (10): 1015-22.

Kable, Joseph W., and Paul W. Glimcher. 2007. "The Neural Correlates of Subjective Value during Intertemporal Choice." Nature Neuroscience 10 (12): 1625-33.

Kahneman, Daniel. 1992. "Reference Points, Anchors, Norms, and Mixed Feelings." Organizational Behavior and Human Decision Processes 51 (2): 296-312.

Kahneman, Daniel, Paul Slovic, and Amos Tversky, eds. 1982. Judgment under Uncertainty: Heuristics and Biases. Cambridge and New York: Cambridge University Press.

Kahneman, Daniel, and Amos Tversky. 1982. "On the Study of Statistical Intuitions." In Judgment under Uncertainty: Heuristics and Biases, edited by Daniel Kahneman, Paul Slovic, and Amos Tversky, 493-508. Cambridge and New York: Cambridge University Press.

-Kamenica, Emir. 2008. "Contextual Inference in Markets: On the Informational Content of Product Lines." American Economic Review 98 (5): 2127-49.

Kang, Min Jeong, and Colin F. Camerer. 2013. "fMRI Evidence of a Hot-Cold Empathy Gap in Hypothetical and Real Aversive Choices." Frontiers in Decision 
Neuroscience 7: 104.

-Kang, Min Jeong, Antonio Rangel, Mickael Camus, and Colin F. Camerer. 2011. "Hypothetical and Real Choice Differentially Activate Common Valuation Areas." Journal of Neuroscience 31 (2): 461-68.

Kishida, Kenneth T., Brooks King-Casas, and P. Read Montague. 2010. "Neuroeconomic Approaches to Mental Disorders." Neuron 67 (4): 543-54.

Koszegi, Botond, and Matthew Rabin. 2006. "A Model of Reference-Dependent Preferences." Quarterly Journal of Economics 121 (4): 1133-65.

Kreps, David M., and Evan L. Porteus. 1978. “Temporal Resolution of Uncertainty and Dynamic Choice Theory." Econometrica 46 (1): 185-200.

-Laibson, David. 1997. "Golden Eggs and Hyperbolic Discounting." Quarterly Journal of Economics 112 (2): 443-77.

-Laibson, David. 2001. "A Cue-Theory of Consumption." Quarterly Journal of Economics 116 (1): 81-119.

-Laibson, David, and Richard Zeckhauser. 1998. "Amos Tversky and the Ascent of Behavioral Economics." Journal of Risk and Uncertainty 16 (1): 7-47.

Lakshminaryanan, Venkat, M. Keith Chen, and Laurie R. Santos. 2008. "Endowment Effect in Capuchin Monkeys." Philosophical Transactions of the Royal Society B: Biological Sciences 363 (1511): 3837-44.

L Latty, Tanya, and Madeleine Beekman. 2011. "Irrational Decision-Making in an Amoeboid Organism: Transitivity and Context-Dependent Preferences." Proceedings of the Royal Society B: Biological Sciences 278 (1703): 307-12.

Levy, Ifat, Jason Snell, Amy J. Nelson, Aldo Rustichini, and Paul W. Glimcher. 2010. "Neural Representation of Subjective Value under Risk and Ambiguity." Journal of Neurophysiology 103 (2): 1036-47.

Lipman, Barton L., and Wolfgang Pesendorfer. 2013. "Temptation."

In Advances in Economics and Econometrics: Tenth World Congress, Volume 1: Economic Theory, edited by Daron Acemoglu, Manuel Arellano, and Eddie Dekel, 243-88. Cambridge and New York: Cambridge University Press.

Loewenstein, George. 1987. "Anticipation and the Valuation of Delayed Consumption." Economic Journal 97 (387): 666-84.

- Loewenstein, George. 2000. "Emotions in Economic Theory and Economic Behavior." American Economic Review 90 (2): 426-32.

Loewenstein, George, and Ted O'Donoghue. 2007. "Animal Spirits: Affective and Deliberative Processes in Economic Behavior." Unpublished.

- Loomes, Graham, and Robert Sugden. 1987. "Testing for Regret and Disappointment in Choice under Uncertainty." Economic Journal 97: 118-29.

Louie, Kenway, Lauren E. Grattan, and Paul W. Glimcher. 2011." "Rewards Value-Based Gain Control: Divisive Normalization in Parietal Cortex." Journal of Neuroscience 31 (29): 10627-39.

-Luo, Shan, George Ainslie, Lisa Giragosian, and John R. Monterosso. 2009. "Behavioral and Neural
Evidence of Incentive Bias for Immediate Rewards Relative to Preference-Matched Delayed Rewards." Journal of Neuroscience 29 (47): 14820-27.

- Markowitz, H. 1952. "The Utility of Wealth." Journal of Political Economy 60 (2): 151-58.

- Markowitz, Harry M. 1991. "Foundations of Portfolio Theory." Journal of Finance 46 (2): 469-77.

- McClure, Samuel M., Keith M. Ericson, David I. Laibson, George Loewenstein, and Jonathan D. Cohen. 2007. "Time Discounting for Primary Rewards." Journal of Neuroscience 27 (21): 5796-804.

- McClure, Samuel M., David I. Laibson, George Loewenstein, and Jonathan D. Cohen. 2004. "Separate Neural Systems Value Immediate and Delayed Monetary Rewards." Science 306 (5695): 503-07.

McFadden, Daniel. 1974. "Conditional Logit Analysis of Qualitative Choice Behavior." In Frontiers in Econometrics, edited by Paul Zarembka, 105-42. New York: Academic Press.

-McFadden, Daniel. 2001. "Economic Choices." American Economic Review 91 (3): 351-78.

- Murayama, Kou, Madoka Matsumoto, Keise Izuma, Kenji Matsumoto. 2010. "Neural Basis of the Undermining Effect of Monetary Reward on Intrinsic Motivation." Proceedings of the National Academy of Sciences 107 (49): 20911-16.

-Padoa-Schioppa, Camillo. 2009. "Range-Adapting Representation of Economic Value in the Orbitofrontal Cortex." Journal of Neuroscience 29 (44): 14004-14.

- Padoa-Schioppa, Camillo, and John A. Assad. 2006. "Neurons in the Orbitofrontal Cortex Encode Economic Value." Nature 441 (7090): 223-26.

Pareto, Vilfredo. 1971. Manual of Political Economy. New York: Kelley, 1909.

Payne, John W., James R. Bettman, and Eric J. Johnson. 1993. The Adaptive Decision Maker. Cambridge and New York: Cambridge University Press.

-Peters, Jan, and Christian Büchel. 2010. "Episodic Future Thinking Reduces Reward Delay Discounting through an Enhancement of Prefrontal-Mediotemporal Interactions." Neuron 66 (1): 138-48.

-Platt, Michael L., and Paul W. Glimcher. 1999. "Neural Correlates of Decision Variables in Parietal Cortex." Nature 400 (6741): 233-38.

- Rangel, Antonio, Colin F. Camerer, and P. Read Montague. 2008. "A Framework for Studying the Neurobiology of Value-Based Decision Making." Nature Reviews Neuroscience 9 (7): 545-56.

Reutskaja, Elena, Axel Lindner, Rosemarie Nagel, Richard Andersen, and Colin F. Camerer. 2011. "Neural Signatures of Choice Overload." Unpublished.

-Rilling, James K., and Alan G. Sanfey. 2011. "The Neuroscience of Social Decision-Making." Annual Review of Psychology 62: 23-48.

- Romer, Paul M. 2000. "Thinking and Feeling." American Economic Review 90 (2): 439-43.

- Rosati, Alexandra G., Jeffrey R. Stevens, Brian Hare, and Marc D. Hauser. 2007. "The Evolutionary Origins of Human Patience: Temporal Preferences in Chimpanzees, Bonobos, and Human Adults." Current Biology 17 (19): 1663-68. 
Rubinstein, Ariel, and Yuval Salant. 2006. "A Model of Choice from Lists.” Theoretical Economics 1 (1): 3-17.

-Rutledge, Robb B., Mark Dean, Andrew Caplin, and Paul W. Glimcher. 2010. "Testing the Reward Prediction Error Hypothesis with an Axiomatic Model." Journal of Neuroscience 30 (40): 13525-36.

-Sallet, J., et al. 2011. "Social Network Size Affects Neural Circuits in Macaques." Science 334 (6056): $697-700$.

- Schultz, Wolfram, Peter Dayan, and P. Read Montague. 1997. "A Neural Substrate of Prediction and Reward.” Science 275 (5306): 1593-99.

- Schwartz, Odelia, and Eero P. Simoncelli. 2001. "Natural Signal Statistics and Sensory Gain Control." Nature Neuroscience 4 (8): 819-25.

- Sell, Aaron, John Tooby, and Leda Cosmides. 2009. "Formidability and the Logic of Human Anger." Proceedings of the National Academy of Sciences 106 (35): 15073-78.

-Sellitto, Manuela, Elisa Ciaramelli, and Giuseppe di Pellegrino. 2010. "Myopic Discounting of Future Rewards after Medial Orbitofrontal Damage in Humans." Journal of Neuroscience 30 (49): 16429-36.

-Selten, Reinhard. 1975. "Reexamination of the Perfectness Concept for Equilibrium Points in Extensive Games." International Journal of Game Theory 4 (1): 25-55.

- Shafir, Sharoni, Tom A. Waite, and Brian H. Smith. 2002. "Context-Dependent Violations of Rational Choice in Honeybees (Apis mellifera) and Gray Jays (Perisoreus canadensis)." Behavioral Ecology and Sociobiology 51 (2): 180-87.

Smith, Alec, B. Douglas Bernheim, Colin F. Camerer, and Antonio Rangel. Forthcoming. "Neural Activity Reveals Preferences without Choices." American Economic Journal: Microeconomics.

Smith, Alec, Terry Lohrenz, Justin King, P. Read Montague, and Colin F. Camerer. 2013. "Irrational Exuberance and Neural Warning Signals during Endogenous Experimental Market Bubbles." Unpublished.

-Sokol-Hessner, Peter, Colin F. Camerer, and Elizabeth A. Phelps. 2013. "Emotion Regulation Reduces Loss Aversion and Decreases Amygdala Responses to Losses." Social Cognitive and Affective Neuroscience 8 (3): 341-50.

-Sokol-Hessner, Peter, Ming Hsu, Nina G. Curley, Mauricio R. Delgado, Colin F. Camerer, and Elizabeth A. Phelps. 2009. “Thinking Like a Trader Selectively Reduces Individuals' Loss Aversion." Proceedings of the National Academy of Sciences 106 (13): 5035-40.

Soltani, Alireza, Benedetto De Martino, and Colin F. Camerer. 2012. "A Range-Normalization Model of Context-Dependent Choice: A New Model and Evidence." PloS Computational Biology 8 (7).

$\checkmark$ Spiegler, Ran. 2008. "Comments on the Potential
Significance of Neuroeconomics for Economic Theory." Economics and Philosophy 24 (3): 515-21.

Spiegler, Ran. 2013. "Comments on 'Behavioral' Decision Theory." In Advances in Economics and Econometrics: Tenth World Congress, Volume 1: Economic Theory, edited by Daron Acemoglu, Manuel Arellano, and Eddie Dekel, 289-304. Cambridge and New York: Cambridge University Press.

Sutton, Richard S., and Andrew G. Barto. 1998. Reinforcement Learning: An Introduction. Cambridge and London: MIT Press.

Thaler, Richard H., and H. M. Shefrin. 1981. “An Economic Theory of Self-Control.” Journal of Political Economy 89 (2): 392-406.

Thevarajah, Dhushan, Ryan Webb, Christopher Ferrall, and Michael C. Dorris. 2010. "Modeling the Value of Strategic Actions in the Superior Colliculus." Frontiers in Behavioral Neuroscience 3: 57.

-Thurstone, Louis Leon. 1927. "A Law of Comparative Judgment.” Psychological Review 34 (4): 278-86.

-Tom, Sabrina M., Craig R. Fox, Christopher Trepel, and Russell A. Poldrack. 2007. "The Neural Basis of Loss Aversion in Decision-Making under Risk.” Science 315 (5811): 515-18.

Tricomi, Elizabeth, Bernard W. Balleine, and John P. O’Doherty. 2009. "A Specific Role for Posterior Dorsolateral Striatum in Human Habit Learning.” European Journal of Neuroscience 29 (11): 2225-32.

Tversky, Amos. 1972. "Elimination By Aspects: A Theory of Choice." Psychological Review 79 (4): 281-99.

-Tversky, Amos, and Daniel Kahneman. 1974. "Judgment under Uncertainty: Heuristics and Biases." Science 185 (4157): 1124-31.

-Tversky, Amos, and Daniel Kahneman. 1981. "The Framing of Decisions and the Psychology of Choice." Science 211 (4481): 453-58.

-Tversky, Amos, and Shmuel Sattath. 1979. "Preference Trees." Psychological Review 86 (6): 542-73.

-Tversky, Amos, and Itamar Simonson. 1993. "ContextDependent Preferences.” Management Science 39 (10): 1179-89.

-Valenza, Eloisa, Francesca Simion, Viola Macchi Cassia, and Carlo Umiltà. 1996. "Face Preference at Birth." Journal of Experimental Psychology: Human Perception and Performance 22 (4): 892-903.

-Yacubian, Juliana, Jan Gläscher, Katrin Schroeder, Tobias Sommer, Dieter F. Braus, and Christian Büchel. 2006. "Dissociable Systems for Gain- and Loss-Related Value Predictions and Errors of Prediction in the Human Brain." Journal of Neuroscience 26 (37): 9530-37.

Zhu, Lusha, Kyle E. Mathewson, and Ming Hsu. 2012. "Dissociable Neural Representations of Reinforcement and Belief Prediction Errors Underlie Strategic Learning." Proceedings of the National Academy of Sciences 109 (5): 1419-24. 